\title{
Automated Capillary Electrophoresis System Compatible with Multiple Detectors for Potential In Situ Spaceflight Missions
}

Konstantin Zamuruyev $\$$, Mauro S. Ferreira Santos $\$$, Maria F. Mora, Emily A. Kurfman ${ }^{\dagger}$, Aaron C. Noell, Peter A. Willis*

Jet Propulsion Laboratory, California Institute of Technology, Pasadena, California, USA

*To whom correspondence should be addressed: peter.a.willis@jpl.nasa.gov

${ }^{\ddagger}$ Authors contributed equally to the manuscript

${ }^{\dagger}$ Present address: Department of Chemistry, University of Kansas, Lawrence, Kansas, USA. 
Supporting Information

\section{Table of Contents}

1 Detailed Description of Pneumatic and Fluidic Valves ................................................ -3

2 Graphical User Interface and Operational Sequences ............................................... -3

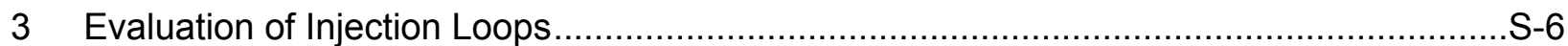

4 Inter-day Repeatability and Reproducibility ........................................................... 


\section{Detailed Description of Pneumatic and Fluidic Valves}

The pneumatic outlet valve is an eighteen-port, nine-position coupler valve. There is one chordal cavity in its rotor. The valve makes nine port pairs, i.e., each rotary position connects two neighboring ports. Eight of the pairs provide a pneumatic outlet path from each of the fluidic reservoirs to the waste reservoir. The waste reservoir is open to atmosphere. An extra pair of ports establishes a pneumatic connection between the headspaces of HV and GND reservoirs. This connection is required to equilibrate the pressure between the two reservoirs during CE separations (to avoid siphoning effects), or to apply a head pressure at both ends of the capillary during separations.

The fluidic selector valve is a seven-port, six-position selector valve. There is one radial cavity in its rotor plate. The valve is configured with six radial ports as inlets and one central port as a common outlet. It provides inflow of fluids from one of the five fluidic reservoirs (BGE, water, $\mathrm{MeOH}, \mathrm{NaOH}, \mathrm{HCl}$ ) into the system.

The fluidic router valve is a seven-port, twelve-position selector-coupler valve. There are two passages in its rotor plate; one radial and one chordal. The chordal cavity is $180^{\circ}$ opposite from the radial cavity. The radial cavity connects the central common port with one of its radial ports (selector, at odd positions). The chordal cavity connects two neighboring radial ports (coupler, at even positions). The angular positions of the two cavities are offset by a half step, so that the valve can operate either as a selector or as a coupler valve. When used as a selector valve, it accepts fluid inflow into its common central port and routes it to one of its radial outlet ports: HV, GND, or waste reservoirs. The ability to couple two neighboring radial ports is used for a dual purpose: to empty HV or GND reservoirs and establish HV isolation. This design of the selector-coupler valve makes it possible for each CE reservoir, HV or GND, to have only one fluidic line for filling or emptying. Therefore, the number of fluidic, and potentially electrical, connections between the HV reservoir and the rest of the fluidic circuit is minimized.

\section{Graphical User Interface and Operational Sequences}

When the system is operated in manual mode, the GUI works as a command input panel. An operator can change the set values for pneumatic pressure, HV level, and positions of the valves. The actual values are graphically displayed on the screen. A screen shot of the graphical interface developed is shown in Figure S1. 


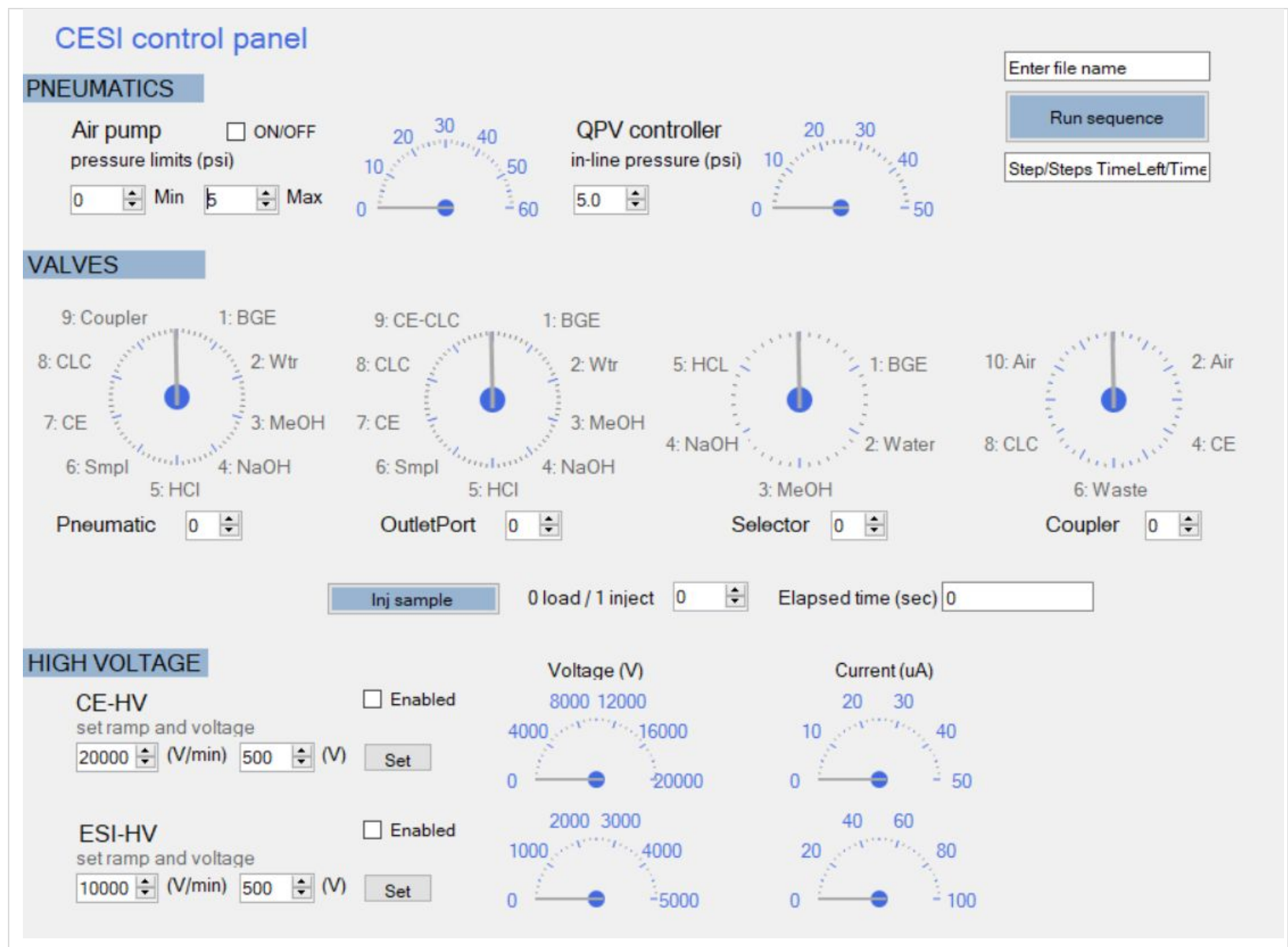

Figure S1. Screen shot of the user-friendly graphical interface.

In automated mode, the GUI operates as a display panel and accepts only a limited number of commands from an operator. After an SD card with an appropriate sequence of commands is inserted into Teensy SD card slot, an operator can execute the sequence or stop it in case something goes wrong. Although the input of commands is disabled in automated mode, an operator can see the actual values as the uploaded sequence is executed.

The state of the system is defined with a numerical array of 16 numbers. To write a longer sequence for an analytical method, one needs to make a matrix with 16 columns and as many rows as the number of operations required by a method. To simplify this task, an excel spreadsheet listing all possible operations and the corresponding array of numerical values was created ("the truth table"). An example of a set of commands available on the truth table is shown in Figure S2. 


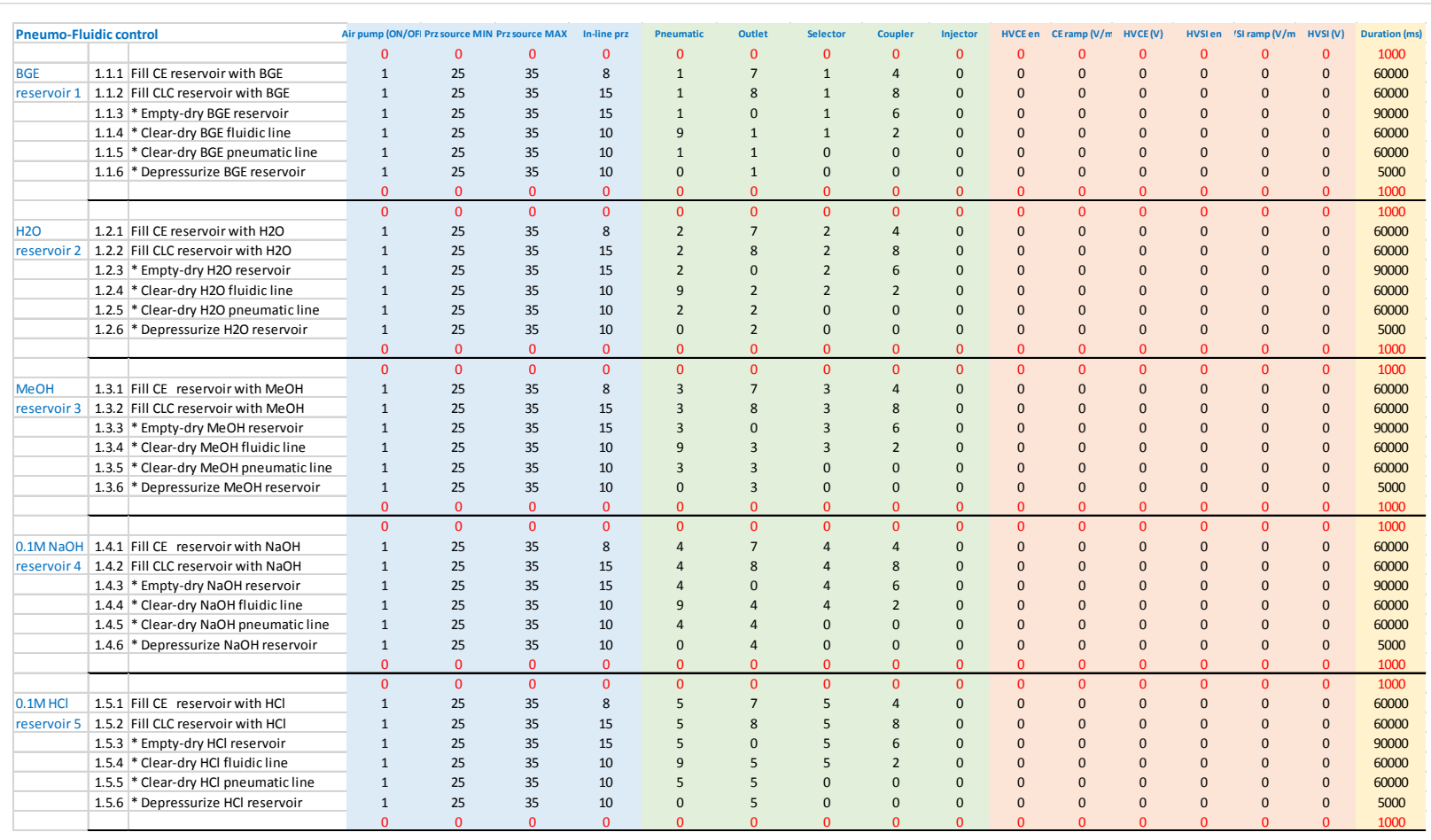

Figure S2. An example of a set of commands and the corresponding numerical values to define the state of the system.

The user can just copy and paste from "the truth table" to create a new sequence of operation. For example: fill HV reservoir with each of the reagents, clear and purge fluidic lines, inject sample, apply HV. These individual operations can be combined into groups. Once the analytical method is developed, an operator can arrange these operations in the desired sequence in a spreadsheet document adjusting the values for pressure, voltage, and time for duration of each step in the sequence, and then copy the corresponding numerical matrix into a file saved on the SD card. The microcontroller will read the matrix and execute it. An example of an analytical method for triplicate analyses using CE-C ${ }^{4} D$ is shown in Figure $S 3$. 


\begin{tabular}{|c|c|c|c|c|c|c|c|c|c|c|c|c|c|c|c|c|c|c|}
\hline \multicolumn{2}{|c|}{ CE-C4D Analysis (3) } & \multicolumn{4}{|c|}{ Air pump (ON/OPrz source MINrz source MA: } & In-line prz & \multirow{2}{*}{$\begin{array}{c}\text { Pneumatic } \\
0\end{array}$} & \multirow{2}{*}{$\begin{array}{c}\text { Outlet } \\
0\end{array}$} & \multirow{2}{*}{$\begin{array}{c}\text { Selector } \\
0\end{array}$} & \multirow{2}{*}{$\begin{array}{c}\text { Coupler } \\
0\end{array}$} & \multirow{2}{*}{$\begin{array}{c}\text { Injector } \\
0\end{array}$} & \multirow{2}{*}{$\begin{array}{c}\text { HVCEen } \\
0\end{array}$} & \multirow{2}{*}{$\begin{array}{c}\text { CEramp }(\mathrm{N} / \mathrm{m} \\
20000\end{array}$} & \multirow{2}{*}{$\begin{array}{l}\text { HVCE(V) } \\
500\end{array}$} & \multirow{2}{*}{$\begin{array}{c}\text { HVSlen } \\
0\end{array}$} & \multirow{2}{*}{$\begin{array}{c}15 \mathrm{Iramp}(\mathrm{V} / \mathrm{m} \\
0\end{array}$} & \multirow{2}{*}{$\begin{array}{c}\text { HVSI (V) } \\
0\end{array}$} & \multirow{2}{*}{$\begin{array}{c}\text { Duration (ms) } \\
10000\end{array}$} \\
\hline & 1 & Define system state & 0 & 0 & 0 & 0 & & & & & & & & & & & & \\
\hline & 2 & Rinse CE capillary @ 1 (inject) & 1 & 25 & 35 & 20 & 7 & 8 & 0 & 0 & 1 & 0 & 20000 & 500 & 0 & 0 & 0 & 30000 \\
\hline & 3 & Rinse CE capillary @ 0 (load) & 1 & 25 & 35 & 20 & 7 & 8 & 0 & 0 & 0 & 0 & 20000 & 500 & 0 & 0 & 0 & 120000 \\
\hline & 4 & Rinse CE capillary @ o (load) & 1 & 25 & 35 & 10 & 7 & 8 & 0 & 0 & 0 & 0 & 20000 & 500 & 0 & 0 & 0 & 10000 \\
\hline & 5 & Release prz in CE reservoir & 1 & 25 & 35 & 5 & 0 & 7 & 0 & 0 & 0 & 0 & 20000 & 500 & 0 & 0 & 0 & 15000 \\
\hline Injection & 6 & Load sample plug & 1 & 25 & 35 & 5 & 6 & 0 & 0 & 0 & 0 & 0 & 20000 & 500 & 0 & 0 & 0 & 10000 \\
\hline \multirow{9}{*}{1} & 7 & Inject sample plug & 1 & 25 & 35 & 5 & 6 & 0 & 0 & 0 & 1 & 0 & 20000 & 500 & 0 & 0 & 0 & 10000 \\
\hline & 8 & Turn on HV for CE separation : & 0 & 0 & 35 & 0 & 0 & 6 & 0 & 0 & 1 & 1 & 40000 & 6000 & 0 & 0 & 0 & 10000 \\
\hline & 9 & Turn on HV for CE separation : & 0 & 0 & 35 & 0 & 1 & 1 & 0 & 0 & 1 & 1 & 40000 & 6000 & 0 & 0 & 0 & 10000 \\
\hline & 10 & Separation CE & 0 & 0 & 35 & 0 & 0 & 9 & 0 & 0 & 1 & 1 & 40000 & 6000 & 0 & 0 & 0 & 600000 \\
\hline & 11 & Turn off HV & 0 & 0 & 35 & 0 & 0 & 9 & 0 & 0 & 1 & 0 & 20000 & 500 & 0 & 0 & 0 & 5000 \\
\hline & 12 & Rinse CE capillary @ 1 (inject) & 1 & 25 & 35 & 20 & 7 & 8 & 0 & 0 & 1 & 0 & 20000 & 500 & 0 & 0 & 0 & 30000 \\
\hline & 13 & Rinse CE capillary @ o (load) & 1 & 25 & 35 & 20 & 7 & 8 & 0 & 0 & 0 & 0 & 20000 & 500 & 0 & 0 & 0 & 120000 \\
\hline & 14 & Rinse CE capillary @ 0 (load) & 1 & 25 & 35 & 10 & 7 & 8 & 0 & 0 & 0 & 0 & 20000 & 500 & 0 & 0 & 0 & 10000 \\
\hline & 15 & Release prz in CE reservoir & 1 & 25 & 35 & 5 & 0 & 7 & 0 & 0 & 0 & 0 & 20000 & 500 & 0 & 0 & 0 & 15000 \\
\hline Injection & 16 & Load sample plug & 1 & 25 & 35 & 5 & 6 & 0 & 0 & 0 & 0 & 0 & 20000 & 500 & 0 & 0 & 0 & 10000 \\
\hline \multirow[t]{9}{*}{2} & 17 & Inject sample plug & 1 & 25 & 35 & 5 & 6 & 0 & 0 & 0 & 1 & 0 & 20000 & 500 & 0 & 0 & 0 & 10000 \\
\hline & 18 & Turn on HV for CE separation : & 0 & 0 & 35 & 0 & 0 & 6 & 0 & 0 & 1 & 1 & 40000 & 6000 & 0 & 0 & 0 & 10000 \\
\hline & 19 & Turn on HV for CE separation : & 0 & 0 & 35 & 0 & 1 & 1 & 0 & 0 & 1 & 1 & 40000 & 6000 & 0 & 0 & 0 & 10000 \\
\hline & 20 & Separation CE & 0 & 0 & 35 & 0 & 0 & 9 & 0 & 0 & 1 & 1 & 40000 & 6000 & 0 & 0 & 0 & 600000 \\
\hline & 21 & Turn off HV & 0 & 0 & 35 & 0 & 0 & 9 & 0 & 0 & 1 & 0 & 20000 & 500 & 0 & 0 & 0 & 5000 \\
\hline & 22 & Rinse CE capillary @ 1 (inject) & 1 & 25 & 35 & 20 & 7 & 8 & 0 & 0 & 1 & 0 & 20000 & 500 & 0 & 0 & 0 & 30000 \\
\hline & 23 & Rinse CE capillary @ o (load) & 1 & 25 & 35 & 20 & 7 & 8 & 0 & 0 & 0 & 0 & 20000 & 500 & 0 & 0 & 0 & 120000 \\
\hline & 24 & Rinse CE capillary @ o (load) & 1 & 25 & 35 & 10 & 7 & 8 & 0 & 0 & 0 & 0 & 20000 & 500 & 0 & 0 & 0 & 10000 \\
\hline & 25 & Release prz in CE reservoir & 1 & 25 & 35 & 5 & 0 & 7 & 0 & 0 & 0 & 0 & 20000 & 500 & 0 & 0 & 0 & 15000 \\
\hline Injection & 26 & Load sample plug & 1 & 25 & 35 & 5 & 6 & 0 & 0 & 0 & 0 & 0 & 20000 & 500 & 0 & 0 & 0 & 10000 \\
\hline \multirow[t]{6}{*}{3} & 27 & Inject sample plug & 1 & 25 & 35 & 5 & 6 & 0 & 0 & 0 & 1 & 0 & 20000 & 500 & 0 & 0 & 0 & 10000 \\
\hline & 28 & Turn on HV for CE separation : & 0 & 0 & 35 & 0 & 0 & 6 & 0 & 0 & 1 & 1 & 40000 & 6000 & 0 & 0 & 0 & 10000 \\
\hline & 29 & Turn on HV for CE separation : & 0 & 0 & 35 & 0 & 1 & 1 & 0 & 0 & 1 & 1 & 40000 & 6000 & 0 & 0 & 0 & 10000 \\
\hline & 30 & Separation CE & 0 & 0 & 35 & 0 & 0 & 9 & 0 & 0 & 1 & 1 & 40000 & 6000 & 0 & 0 & 0 & 600000 \\
\hline & 31 & Turn off HV & 0 & 0 & 35 & 0 & 0 & 9 & 0 & 0 & 1 & 0 & 20000 & 500 & 0 & 0 & 0 & 5000 \\
\hline & 32 & Define sytem state & 0 & 0 & 0 & 0 & 0 & 0 & 0 & 0 & 0 & 0 & 20000 & 500 & 0 & 0 & 0 & 1000 \\
\hline
\end{tabular}

Figure S3. An example of an analytical method for triplicate runs with CE-C4D, including capillary rinsing (BGE), sample injection, $\mathrm{HV}$ isolation, and $\mathrm{CE}$ separation.

\section{Evaluation of Injection Loops}

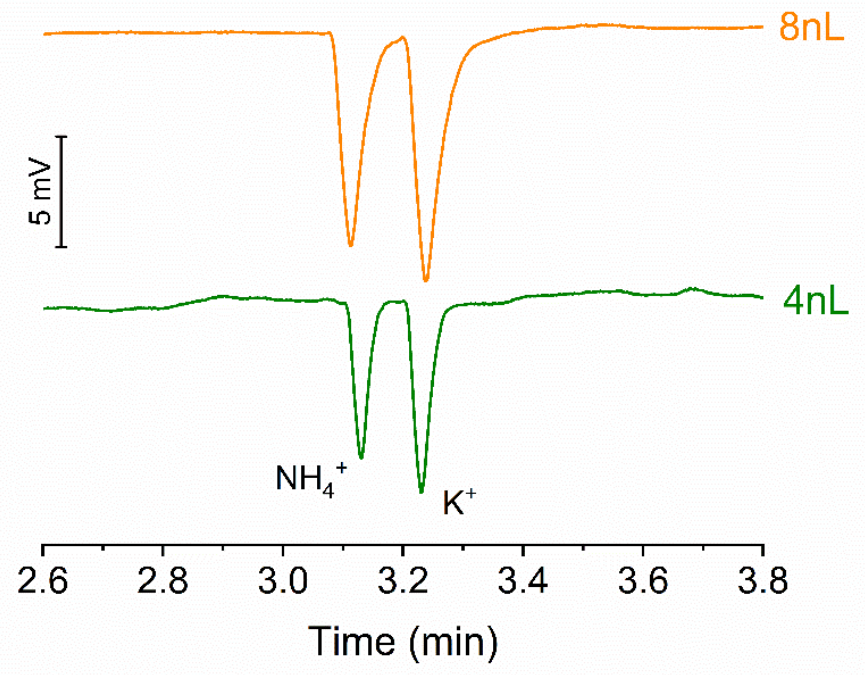

Figure S4. Electropherograms for the injection of $250 \mu \mathrm{M}$ of each $\mathrm{NH}_{4}{ }^{+}$and $\mathrm{K}^{+}$using an $8 \mathrm{~nL}$ and a $4 \mathrm{~nL}$ injection valve in the automated portable CE system. Separations were performed in a $50 \mu \mathrm{m}$ i.d. fused silica capillary of $50 \mathrm{~cm}$ length (45 cm effective length); $5 \mathrm{M}$ acetic acid was used as the BGE. Other conditions: $\mathrm{V}_{\mathrm{SEP}}: 20 \mathrm{kV}$. 


\section{Inter-day Repeatability and Reproducibility}

The average values for migration time and peak height ( \pm standard deviation of 9 runs) are presented in Table S1.

Table S1. Variation of the peak height $(\mathrm{mV})$ and migration time $(\mathrm{min})$ of the selected inorganic cations and amino acids for triplicate analysis performed in three different days (inter-day repeatability and reproducibility, $n=9$ ).

\begin{tabular}{ccccc} 
Analytes & Peak height (mV) & RSD (\%) & Migration time (min) & RSD (\%) \\
\hline $\mathrm{NH}_{4}{ }^{+}$ & $4.46 \pm 0.03$ & $0.7 \%$ & $3.2 \pm 0.04$ & $1.3 \%$ \\
$\mathrm{~K}^{+}$ & $5.05 \pm 0.05$ & $0.9 \%$ & $3.3 \pm 0.04$ & $1.2 \%$ \\
$\mathrm{Ca}^{2+}$ & $11.2 \pm 0.10$ & $1.3 \%$ & $4.0 \pm 0.04$ & $1.1 \%$ \\
$\mathrm{Na}^{+}$ & $9.43 \pm 0.50$ & $5.7 \%$ & $4.2 \pm 0.05$ & $1.1 \%$ \\
$\mathrm{Mg}^{2+}$ & $11.4 \pm 0.8$ & $7.4 \%$ & $4.3 \pm 0.04$ & $1.0 \%$ \\
Li & $5.61 \pm 0.05$ & $0.9 \%$ & $5.0 \pm 0.04$ & $0.9 \%$ \\
b-Ala & $1.20 \pm 0.06$ & $5.3 \%$ & $5.5 \pm 0.05$ & $0.8 \%$ \\
GABA & $1.52 \pm 0.05$ & $3.2 \%$ & $5.8 \pm 0.05$ & $0.8 \%$ \\
His & $1.55 \pm 0.06$ & $3.8 \%$ & $5.9 \pm 0.05$ & $0.8 \%$ \\
Gly & $0.68 \pm 0.04$ & $5.8 \%$ & $6.4 \pm 0.05$ & $0.8 \%$ \\
Ala & $0.76 \pm 0.05$ & $7.0 \%$ & $6.8 \pm 0.05$ & $0.8 \%$ \\
AlB & $0.73 \pm 0.06$ & $7.8 \%$ & $7.1 \pm 0.06$ & $0.8 \%$ \\
Val / Iva & $1.30 \pm 0.04$ & $3.1 \%$ & $7.5 \pm 0.06$ & $0.8 \%$ \\
Ser / Leu & $1.31 \pm 0.08$ & $5.9 \%$ & $7.7 \pm 0.06$ & $0.8 \%$ \\
Glu & $0.54 \pm 0.04$ & $8.0 \%$ & $8.5 \pm 0.07$ & $0.9 \%$ \\
Asp & $0.55 \pm 0.05$ & $9.8 \%$ & $8.9 \pm 0.08$ & \\
\hline
\end{tabular}

